\title{
Biochar Effects on Nutrients Retention and Release of Hydroponics Growth Media
}

\author{
Mohammed Taha Haraz ${ }^{1,2}$, Les Bowtell ${ }^{1} \&$ Raed A. Al-Juboori ${ }^{3}$ \\ ${ }^{1}$ Faculty of Health, Engineering and Sciences, University of Southern Queensland, Australia \\ ${ }^{2}$ Department of Horticulture and Landscape, College of Agriculture, University of Diyala, Iraq \\ ${ }^{3}$ Water Engineering Research Group, Department of Civil and Environmental Engineering, Aalto University, \\ Aalto, Espoo, Finland \\ Correspondence: Mohammed Taha Haraz, Faculty of Health, Engineering and Sciences, University of Southern \\ Queensland, Australia. E-mail: haraz.haraz@usq.edu.au
}

Received: May 8, 2020

doi:10.5539/jas.v12n8p1

\author{
Accepted: June 9, $2020 \quad$ Online Published: July 15, 2020 \\ URL: https://doi.org/10.5539/jas.v12n8p1
}

\begin{abstract}
Applying biochar (BC) to broad acre crops is an effective way to sequester carbon while improving soil fertility and reducing nutrient leaching. Adopting a similar approach in a hydroponic environment, BC may enhance nutrient availability and reduce natural fluctuations in the nutrient solution. This study monitored the effect of BC addition to peatmoss growth media with ratios of $0 \%, 5 \%, 25 \%$ and $50 \%$ on $\mathrm{pH}$, electrical conductivity (EC) and macronutrient retention, over 15 days using hydroponic nutrient solution controls. Deionised water was used to measure nutrient releases in the closed loop hydroponic system, showing that biochar increased $\mathrm{pH}$ level in both retention and release stages. As expected, the $\mathrm{pH}$ increased by a maximum of 1.5 units with the highest biochar to growth media ratio due to the natural liming nature of the $\mathrm{BC}$. The $\mathrm{EC}$ was also affected, as $\mathrm{BC}$ increased in the media EC reduced. With regards to retention of nutrients, $\mathrm{BC}$ recovered nitrate, phosphate, calcium and sulphate but did not affect magnesium. Potassium levels increased in solution with increasing $\mathrm{BC}$ ratio. In terms of outcomes relevant to global agriculture, the results show that the same level of production can nominally be obtained with around half the nutrient requirements.
\end{abstract}

Keywords: biochar, hydroponics, macronutrients, release, retention

\section{Introduction}

The World's population is expected to reach 9.7 billion by 2050. It is estimated that there will be more than $50 \%$ loss of arable land per capita by 2050 in comparison to 1960 (Bruinsma, 2011). New systems should be introduced to meet the rapidly growing demands of food while minimizing the consumption of natural resources and cost (Gashgari et al., 2018). Hydroponics is a proven method to increase crop quality and quantity (Davidson \& Szmidt, 1992). In Hydroponic method, growth media other than soils such as rock-wool, sand, peatmoss, perlite, vermiculite and others is normally used. There are many types of hydroponics, however, the recycling of used nutrients solution (closed system) was used as it is the most eco-friendly system (Bar-Yosef, 2008) as it increases nutrient and water use efficiency while at the same time reducing the cost of production (Rouphael et al., 2004; Grewal et al., 2011). It was also shown that recycling nutrients save water and fertiliser, while reducing water pollution (Savvas, 2002; Carmassi et al., 2005). When comparing between hydroponic and traditional cultivation, the former is considered better due to its potential to cover future food demands in a sustainable way (Gashgari et al., 2018). In a study done by Barbosa et al. (2015), comparing conventional agriculture to hydroponics using lettuce as a test plant, hydroponics offered around 11 times higher yield than traditional approaches. In another study that compared tomato cultivation in hydroponics and soil-based agriculture, the closed cycle hydroponic system approach was found to be better in terms of yield and water use efficacy (Valenzano et al., 2008).

Biochar made from coconut shell biochar (CSBC) is the targeted material in this study. The availability of information on biochar used in hydroponic growth media is far less than that for use in soil cultivation systems. Biochar is a carbon rich product that can be obtained from wood, leaves or manure, heated at high temperature (usually $450-1000{ }^{\circ} \mathrm{C}$ ) in a closed environment with a little or no air (Lehmann, 2007). Biochar types, chemical and physical properties can vary depending on pyrolysis conditions and feedstocks (Keiluweit et al., 2010). Graber 
et al. (2010) reported that biochar improved pepper (Capsicum annuum L.) and tomato (Lycopersicum esculentum Mill.) growth and productivity. It was also reported by Glaser et al. (2002) that biochar significantly improved nutrient availability to plants and plant productivity. Beck et al. (2011) showed that the amendment of green roof media with 7\% biochar decreased phosphate and nitrate leaching in runoff and increased water retention. Adding biochar to hydroponics improved microbial population and reduced nutrients runoff such as nitrate and phosphate (Altland \& Locke, 2012).

In terms of growth media, coconut peat, sometimes called peatmoss or coir, is a widely used material for plant growth in pots, containers and plastic tube for traditional or hydroponic cultivation approaches. This media can be used by itself or mixed with other materials such perlite, vermiculite and occasionally soil (Hochmuth et al., 1998). Coco-peat is a very common soilless media as it is cheap and eco-friendly. However, this media cannot hold nutrients as well as biochar, so lab tests were developed to examine this hypothesis in this study. There are a few problems with using coco-peat, this research focused on two of these issues and they are $\mathrm{pH}$ and nutrient holding capacity compared with biochar (United States Environmental Protection Agency Office of Solid Waste, 1994). Coco-peat is acidic with a $\mathrm{pH}$ range of 4-5, which is not suitable for most of the nutrients absorbed by plants. Most growers tend to add dolomite or other materials to the growth media to bring $\mathrm{pH}$ level from 4-5 to circa 5.5-6. Coco-peat was used in this trial to leverage the effect of biochar on $\mathrm{pH}, \mathrm{EC}$, and plants major nutrient elements $\left(\mathrm{N}-\mathrm{NO}_{3}, \mathrm{P}_{-} \mathrm{PO}_{4}, \mathrm{~K}, \mathrm{Ca}, \mathrm{Mg}\right.$ and $\left.\mathrm{S}-\mathrm{SO}_{4}\right)$ in a closed hydroponic system in a lab environment. The aim of this research is to test the use of CSBC with peatmoss for controlling nutrients mobility. CSBC is well known by its capacity of rising $\mathrm{pH}$ level and nutrient retention, it can be mixed with coco-peat as growth media to bring $\mathrm{pH}$ level up and increase nutrient holding capacity of peatmoss and CSBC mixture. We also propose alternating nutrients provision cycles with tap water cycles to increase the efficiency of nutrients utilization. It is important to mention that there are very limited or no study conducted on the effect of biochar on sulphate and this could be the first study to investigate biochar effect on sulphate. It is also the first study that monitors biochar effect on $\mathrm{pH}, \mathrm{EC}$, and the whole plants' macronutrients because there is interaction between these nutrients as well as interactions between the nutrients and $\mathrm{pH}$.

\section{Materials and Methods}

\subsection{Experiment Setup}

Figure 1 shows a simplified schematic of the experimental setup along with the composition of columns. The experimental set up consists of the following components:

- Four triple head peristaltic pumps (Thermo Scientific ${ }^{\text {TM }}$ DB3000A) used to feed 12 units supplying deionised water and nutrient solution alternately to the columns.

- The water or the nutrient solution was supplied from holding tanks (Icon Water Carrier 15L) to each column.

- 24 containers ( 12 containers filled with deionised water and the other 12 containers filled with nutrient solution) with each column linked to two containers, one with deionised water and another one with nutrient solution.

- 12 columns, three of them filled with peatmoss only ( $0 \%$ the control treatment) and the other nine columns filled with 5,25 and $50 \% \mathrm{v} / \mathrm{v}$ biochar/peatmoss.

\subsection{Experimental Procedure}

The columns were first fed with deionised water on the first day for around $38 \mathrm{~min} \pm 1 \mathrm{~min}$. Then, the columns were fed in an intermittent fashion where the pumps were turned on for 12 minutes and off for 10 minutes for three cycles. This makes the total feeding time 36 minutes. The 10 minutes off period was found to be enough for the solution to be completely drained and hence it was applied between the feeding time. Samples from the deionised water containers were taken and frozen for later analyses. On the second day, the columns were fed with stock solution applying the same settings for deionized water. The process continued with alternating the feed between deionised water and stock solution for 15 days as detailed in Table 1 . The time settings chosen in this study are in accordance with what farmers use in commercial hydroponic farms. The standard setup is a closed-loop system that offers the most economic and eco-friendly option compared to other hydroponic growing systems (Bar-Yosef 2008; Grewal et al. 2011). 


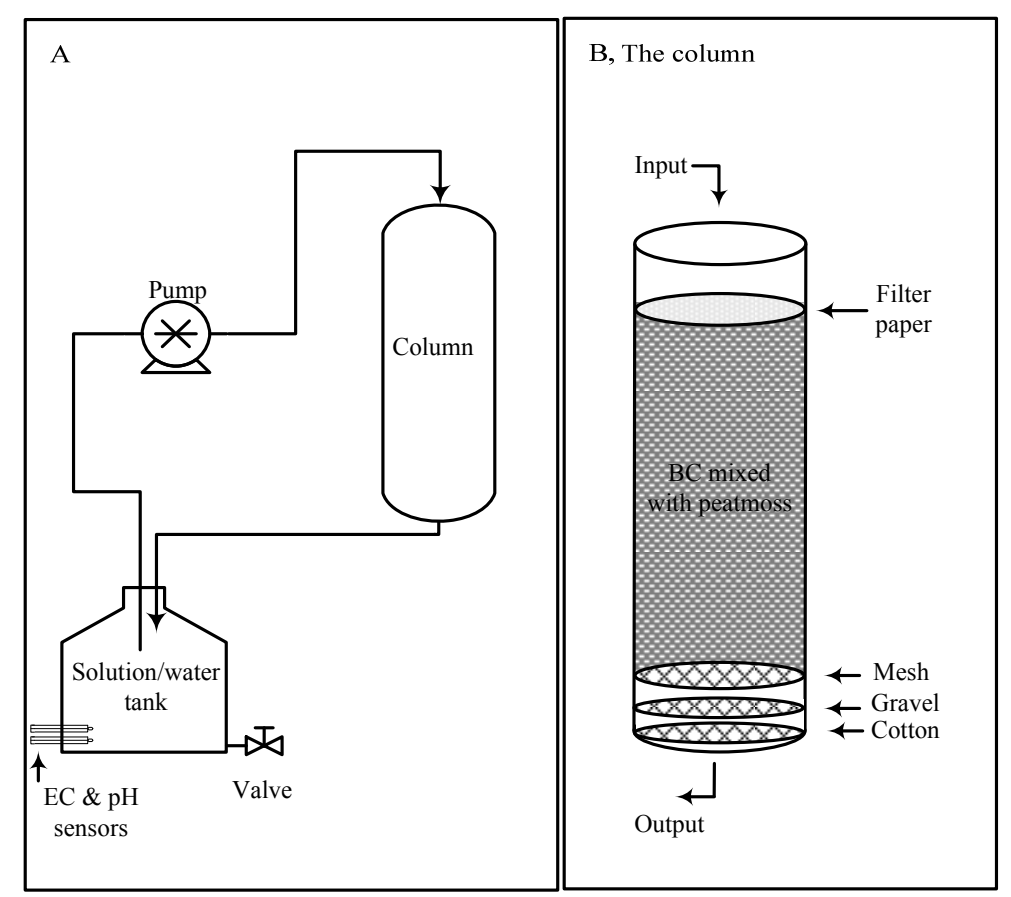

Figure 1. (A) Simplified schematic of the experimental setup, and (B) illustration of column components

\subsection{Substrate Types}

The substrates used in this work comprised of coco-peat (peatmoss) obtained from a local farm (K Farm, Toowoomba, Australia) provided by Aussie Environmental-Australia. CSBC was provided by Clarence Water Filter, Australia. $\mathrm{BC}$ was washed for 4 times to bring the hydroponic solution $\mathrm{pH}$ level down to 5.5-6.5 and to ensure minimal release of caustic mineralised ash into the solution. $\mathrm{BC}$ and peatmoss were sterilised at $120^{\circ} \mathrm{C}$ for 30 min using an autoclave (HICLAVE, HV-50L) to minimise biological activity, then oven-dried at $70^{\circ} \mathrm{C}$ for $24 \mathrm{~h}$. Finally, the prepared substrate was stored in a dry environment in closed containers until they were used.

\subsection{Column Preparation}

The columns were prepared from polyvinyl chloride (PVC) pipe with dimensions of $250 \mathrm{~mm}$ in height and $40 \mathrm{~mm}$ in diameter. PVC and polyethylene fittings size 9, 13, and $15 \mathrm{~mm}$ were used to connect the columns to the pumps and to the stock solution input and output lines. A layer of cotton was placed at the bottom of each column, then a plastic mesh (fibreglass fly screen) with $60 \mu \mathrm{m}$ pore size was laid on the top of the cotton layer. A layer of gravel-sized 2-4 mm was then added on the top of the mesh. The three layers were used to prevent substrates of being washed by the solution. The peatmoss was mixed with $\mathrm{BC}$ (total mixture depth was $200 \mathrm{~mm}$ of the column height) in 4 percentages of 0:100, 5:95, 25:75, and 50:50 v/v BC/peatmoss, respectively. The mixture was then packed into the columns. The columns were gently tapped a few times to let the media settle. A filter paper (Whatman $45 \mu \mathrm{m}$ ) was placed on top of the media to ensure a good distribution of the solution in the column packing materials Figure 1 (B). The columns were closed from both ends with plastic caps that have opening for connecting the inlet and outlet lines simulating a closed hydroponic system, as shown in Figure 1 (A). The columns were then placed in their respective holders and connected to the stock solution containers via the input and output tubes. 
Table 1. Irrigation experiment timing over 15 days

\begin{tabular}{|c|c|c|c|c|c|c|c|c|c|c|c|c|c|c|c|c|}
\hline Biochar ratio & Replicates & Day 1 & Day 2 & Day 3 & Day 4 & Day 5 & Day 6 & Day 7 & Day 8 & Day 9 & Day 10 & Day 11 & Day 12 & Day 13 & Day 14 & Day 15 \\
\hline & R1 & DW & NS & DW & NS & DW & NS & DW & NS & DW & NS & DW & NS & DW & NS & DW \\
\hline \multirow[t]{3}{*}{$0 \% \mathrm{CSBC}$} & $\mathrm{R} 2$ & DW & NS & DW & NS & DW & NS & DW & NS & DW & NS & DW & NS & DW & NS & DW \\
\hline & $\mathrm{R} 3$ & DW & NS & DW & NS & DW & NS & DW & NS & DW & NS & DW & NS & DW & NS & DW \\
\hline & R1 & DW & NS & DW & NS & DW & NS & DW & NS & DW & NS & DW & NS & DW & NS & DW \\
\hline \multirow[t]{3}{*}{$5 \% \mathrm{CSBC}$} & $\mathrm{R} 2$ & DW & NS & DW & NS & DW & NS & DW & NS & DW & NS & DW & NS & DW & NS & DW \\
\hline & R3 & DW & NS & DW & NS & DW & NS & DW & NS & DW & NS & DW & NS & DW & NS & DW \\
\hline & R1 & DW & NS & DW & NS & DW & NS & DW & NS & DW & NS & DW & NS & DW & NS & DW \\
\hline \multirow[t]{3}{*}{$25 \% \mathrm{CSBC}$} & $\mathrm{R} 2$ & DW & NS & DW & NS & DW & NS & DW & NS & DW & NS & DW & NS & DW & NS & DW \\
\hline & $\mathrm{R} 3$ & DW & NS & DW & NS & DW & NS & DW & NS & DW & NS & DW & NS & DW & NS & DW \\
\hline & R1 & DW & NS & DW & NS & DW & NS & DW & NS & DW & NS & DW & NS & DW & NS & DW \\
\hline \multirow[t]{2}{*}{$50 \%$ CSBC } & $\mathrm{R} 2$ & DW & NS & DW & NS & DW & NS & DW & NS & DW & NS & DW & NS & DW & NS & DW \\
\hline & $\mathrm{R} 3$ & DW & NS & DW & NS & DW & NS & DW & NS & DW & NS & DW & NS & DW & NS & DW \\
\hline
\end{tabular}

Note. $\mathrm{DW}=$ Deionised water; NS = Nutrient solution.

\subsection{Substrates and Stock Solution Characterisation}

The characteristics of the substrate and stock solution such as $\mathrm{pH}, \mathrm{EC}$ and the concentration of $\mathrm{NO}_{3}, \mathrm{PO}_{4}, \mathrm{~K}, \mathrm{Ca}$, $\mathrm{Mg}$ and $\mathrm{SO}_{4}$ were examined using $\mathrm{pH}$ and EC (PC 2700 from EUTECH INSTRUMENTS) meters along with Ion Chromatography System ICS-2000 and Atomic Absorption Spectrophotometer AAS-7000 (SHIMADZU, Australia) following the standard methods described in (Rice et al., 2017). The results for peatmoss and stock solutions are presented in Tables 2 and 3. It is worth mentioning that all of the applied measurements were conducted in triplicate to ensure the accuracy of the results.

Deionised water was used as an extraction solution for the peatmoss constituents. Peatmoss was mixed with deionised water in a ratio of $1: 20(\mathrm{w} / \mathrm{w}$, peatmoss to deionised water) and loaded into $100 \mathrm{ml}$ plastic vials. The mixture was shaken at $100 \mathrm{rpm} / \mathrm{min}$ for $24 \mathrm{~h}$. The resultant mixture was then filtered through filter paper (Whatman $45 \mu \mathrm{m}$ ). The filtrate was then used for performing the analyses. Biochar $\mathrm{pH}$ and $\mathrm{EC}$ were also measured following the procedure reported in (Wang et al., 2015a) where 1:20 ratio for BC to deionised water was used.

\subsection{Nutrient Assay}

Samples of the column leachate with retention and release experiments were collected each day and frozen for later analyses. The concentration of solution elements was measured applying the methods described in the above section.

Table 2. Peatmoss characteristics and composition

\begin{tabular}{ll}
\hline Characteristics & Average values \\
\hline $\mathrm{pH}$ & 4.3 \\
$\mathrm{EC}(\mathrm{mS} / \mathrm{cm})$ & 2.3 \\
$\mathrm{TN}(\mathrm{mg} / \mathrm{L})$ & 5.3 \\
Phosphate $(\mathrm{mg} / \mathrm{L})$ & 0.2 \\
Potassium $(\mathrm{mg} / \mathrm{L})$ & 0.3 \\
Calcium $(\mathrm{mg} / \mathrm{L})$ & 1.7 \\
Magnesium $(\mathrm{mg} / \mathrm{L})$ & 1.0 \\
Sulphate $(\mathrm{mg} / \mathrm{L})$ & 0.1 \\
\hline
\end{tabular}


Table 3. Nutrients solution characteristics and composition

\begin{tabular}{ll}
\hline Characteristics & Average values \\
\hline $\mathrm{pH}$ & 6.2 \\
$\mathrm{EC}(\mathrm{mS} / \mathrm{cm})$ & 2.3 \\
Nitrate $(\mathrm{mg} / \mathrm{L})$ & 301.0 \\
Phosphate $(\mathrm{mg} / \mathrm{L})$ & 32.9 \\
Potassium $(\mathrm{mg} / \mathrm{L})$ & 136.6 \\
Calcium $(\mathrm{mg} / \mathrm{L})$ & 140.1 \\
Magnesium $(\mathrm{mg} / \mathrm{L})$ & 18.0 \\
Sulphate $(\mathrm{mg} / \mathrm{L})$ & 157.0 \\
\hline
\end{tabular}

\section{Results and Discussion}

\subsection{Biochar Impact on Leachate $\mathrm{pH}$}

Figure 2 shows the effect of biochar on the $\mathrm{pH}$ of leachate from the column with nutrient solution and deionised water for retention and release events. The values are presented by the mean of three measurements and standard errors. Figure 2(a) illustrates the effect of biochar on $\mathrm{pH}$ for retention events (days 2-14), while Figure 2(b) presents the effect on $\mathrm{pH}$ for the release events (days 1-15). The same presentation applies to the other figures presented in this work.

It can be seen that $\mathrm{pH}$ increased in all treatment scenarios, except for nutrient solution without biochar. This could be attributed to the acidic nature of peatmoss ( $\mathrm{pH}$ of 4.34). The pattern of $\mathrm{pH}$ increase during treatment events was different for the two tested solutions. The level of $\mathrm{pH}$ had a sharp increase with nutrient solution for the first day especially with high BC percentages. Then the increase almost plateaued. In comparison, the increase of $\mathrm{pH}$ level with deionised water exhibited a logarithmic growth curve for all $\mathrm{BC}$ percentages. The maximum $\mathrm{pH}$ increase of 1.2 units was achieved with deionised water using $50 \%$ biochar.

Given the acidic nature of peatmoss, $\mathrm{BC}$ addition can help to bring the $\mathrm{pH}$ to a more neutral level. Increasing $\mathrm{pH}$ level by adding biochar to the growth media could be due to a number of factors. The main one being that biochar may contain nonpyrolyzed inorganic elements, so the exchange of these elements reduces the media's hydrogen concentration (Novak et al., 2009). The increase of $\mathrm{pH}$ to up to 6.0 can increase the yield of leafy crops in hydroponics, which is the case for low percentages of CSBC (Wortman, 2015). However, increasing the pH beyond this level can increase the chlorophyll content, but negatively affects yield. The effect of $\mathrm{pH}$ on plants was also investigated by Koehorst et al. (2010) where low (4.5) and high (8.5) pH significantly reduced plant productivity, while a $\mathrm{pH}$ of 6.5 was found to be the optimum level for producing the best chlorophyll content and fresh leaf weight. Biochar has also been reported to increase $\mathrm{pH}$ level to suit the majority of plant groups in soilless cultivation (Raviv et al., 2019).

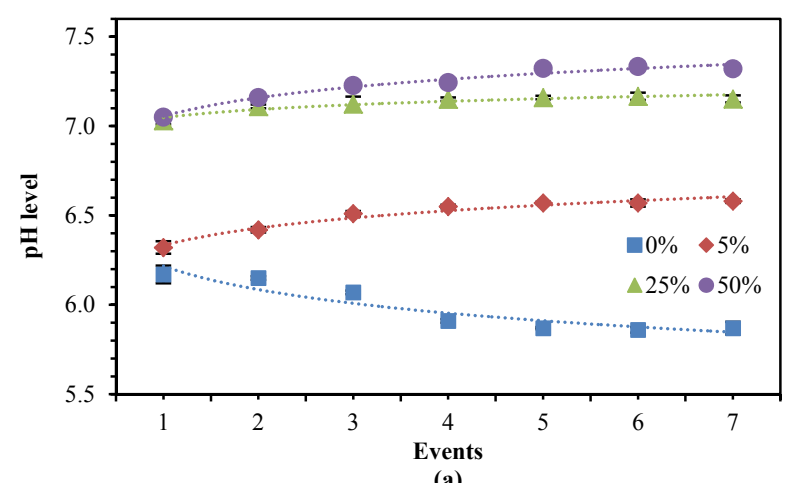

(a)

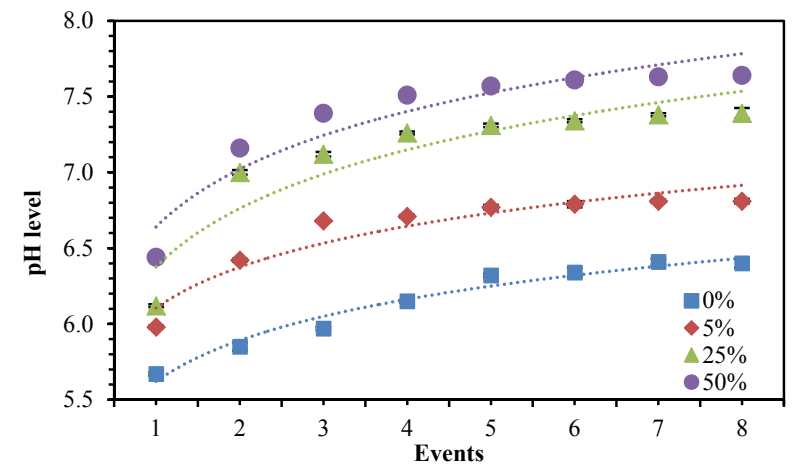

(b)

Figure 2. pH variation of (a) nutrients solution and (b) deionized water 


\subsection{Biochar Impact on EC Level}

Figure 3 illustrates the effect of $\mathrm{BC}$ on $\mathrm{EC}$ during retention and release events. It can be noticed that the retention events led to reducing EC in the columns effluent and vice versa with release events. The variation in EC reflects the change in nutrients concentration in the passing solution through the columns. In general, the increase of the effluent $\mathrm{EC}$ with the release events was higher than the decrease with retention events. The maximum decrease of EC was approximately $837 \mu \mathrm{S}$ achieved with $50 \% \mathrm{BC}$, whereas the maximum increase in EC of $977 \mu \mathrm{S}$ was achieved with $0 \% \mathrm{BC}$. This is due to the strong stripping effect of deionised water and the sorption capacity of BC (Raviv et al., 2019).

Factors such as EC, the type of nutrient, composition of nutrient solution are the key to improve yield quality. Savvas (2002) stated that EC is considered to be one of the most important properties of the nutrient solutions used in soilless cultivation. If the EC of a nutrient solution is too low, the supply of some nutrients to the crop may be inadequate. Similarly, when the EC is too high, the plants are exposed to salinity effects. However, the yield response of the plants to the EC of the nutrient solution may vary widely among different species. Therefore, for each cultivated plant species, the terms "too low" and "too high" need to be quantitatively defined based on experimental results (Putra \& Yuliando, 2015). EC was significantly affected by the biochar amount and with the experiment time for both retention and release events. In any case, EC levels were well below the threshold $(<300$ $\mathrm{mS} \mathrm{m}^{-1}$ ) recommended for soilless substrate fertilising solutions (Raviv et al., 2019).

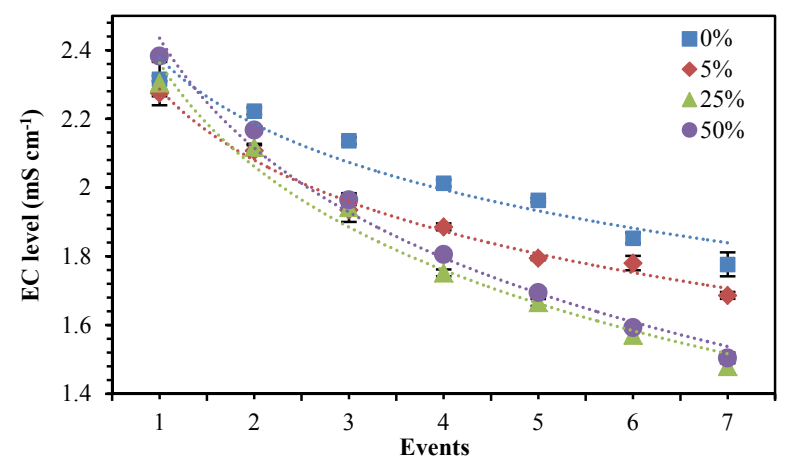

(a)

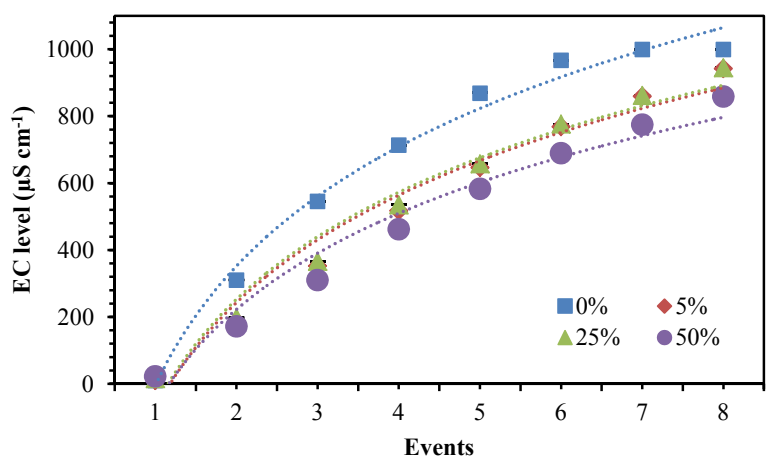

(b)

Figure 3. EC variation of (a) nutrients solution and (b) deionized water

\subsection{Nutrient Behaviour}

The results presented in this section are concerning the effect of biochar on individual constituents of the nutrient solution during retention and release events.

\subsubsection{Biochar Impact on Nitrate Concentration}

The retention of nitrate onto column packing materials and its subsequent release is illustrated in Figures 4 . The retained nitrate concentration had a linear correlation with the frequency of the events. It is apparent that the presence of biochar increased the retention of nitrate in the column. Nitrate retention increased with increasing biochar percentage. The release of nitrate was the highest for $0 \%$ biochar. The amount of nitrate release decreased with increasing percentage of biochar. This is related to the holding capacity of biochar for nitrate. It can be noticed that the released amount of nitrate with $0 \%$ biochar does not follow a linear trend and it plateaued after the sixth day. The recovered amount of nitrate from peatmoss decreases after a certain number of release events. The addition of biochar reduced nitrate in the leachate which is in line with the findings reported in (Ding et al., 2010; Altland \& Locke, 2012; Yao et al., 2012; Gai et al., 2014). Beck et al. (2011) also showed that adding biochar to green roof trays increased nitrate retention. The retention of nitrate onto biochar could be attributed to the electrochemical interaction and binding with the functional groups (Bakly et al., 2019). Steam activation of biochar almost doubled the positive effects of biochars for nutrient retention, and this highlights the need for further investigation for effective application of biochar in hydroponic systems (Borchard et al., 2012). 

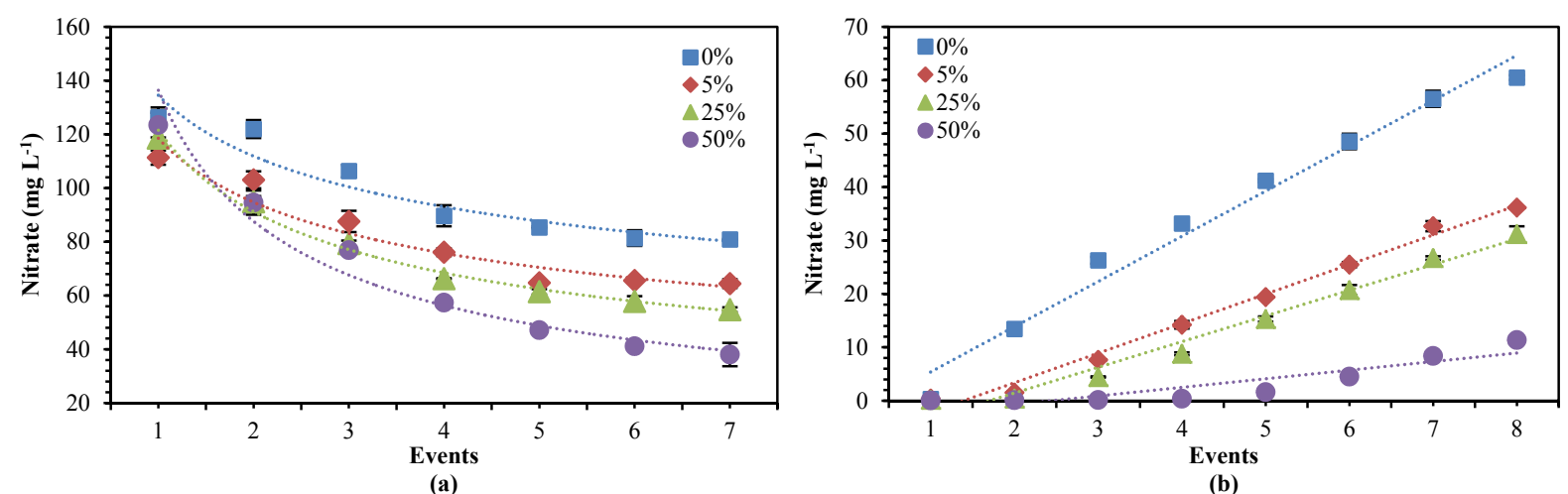

Figure 4. Nitrate concentration during (a) nutrients retention and (b) release

\subsubsection{Biochar Impact on Phosphate Concentration}

Phosphate was retained and released as shown in Figures 5(a) and (b) respectively. It can be noticed that the amount of phosphate absorbed and released by biochar is much less than that of nitrate. This is ascribed to the high concentration and the co-existence effect of nitrate Zhong et al. (2019) and Palanivell et al. (2020). A recent study conducted by Palanivell et al. (2020) showed that biochar has a greater absorption capacity of nitrogen compared to phosphorous and potassium especially for acidic media. Given the acidic nature of peatmoss, this explains the observed difference in nitrate behaviour as opposed to phosphate and potassium (will be addressed in the following section). Similar to nitrate, the adsorption and release exhibited liner correlations with the frequency of the events.

In general, higher percentage of biochar in the media resulted in more retention of phosphate and less releasing. The control treatment retained around $7 \mathrm{mg} \mathrm{L}^{-1}$ whereas $50 \% \mathrm{CSBC}$ retained around $22 \mathrm{mg} \mathrm{L}^{-1}$. The 5 and $25 \%$ treatments retained around $13 \mathrm{mg} \mathrm{L}^{-1}$ and $18 \mathrm{mg} \mathrm{L}^{-1}$, respectively. As phosphate was retained by $\mathrm{BC}$, it was released slowly over the experiment time. The highest release of phosphate was from the control treatment while the lowest was from $50 \%$ CSBC. It was around $27 \mathrm{mg} \mathrm{L}^{-1}$ for $0 \% \mathrm{CSBC}$ and around $17 \mathrm{mg} \mathrm{L}^{-1}$ for $50 \% \mathrm{CSBC}$. The $5 \%$ and $25 \% \mathrm{CSBC}$ treated media released around $22 \mathrm{mg} \mathrm{L}^{-1}$ and $23 \mathrm{mg} \mathrm{L}^{-1}$, respectively. The results of this study are aligned with the findings reported in literature, as biochar was found to be capable of absorbing and slowly releasing phosphate in the leachate (Nelson et al., 2011). However, the capacity of biochar in controlling the mobility of phosphate depends on the feedstock and pyrolysis conditions of the char (Yao et al., 2012). CSBC used was acid washed biochar and this might have improved the retention ability of BC.

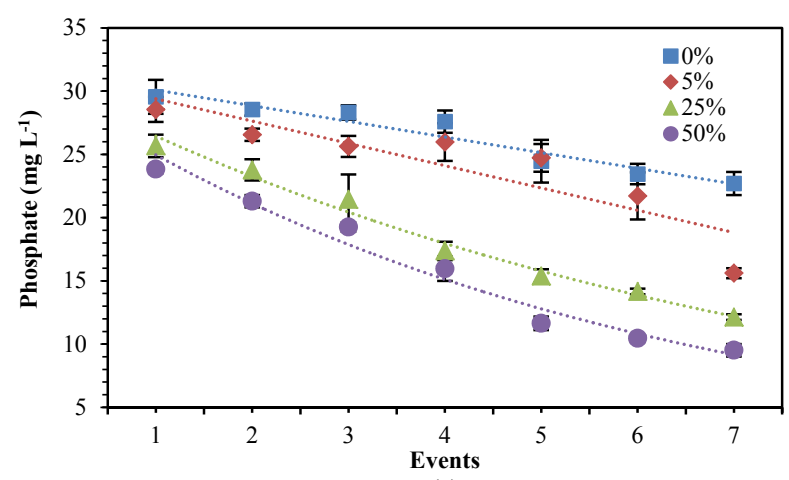

(a)

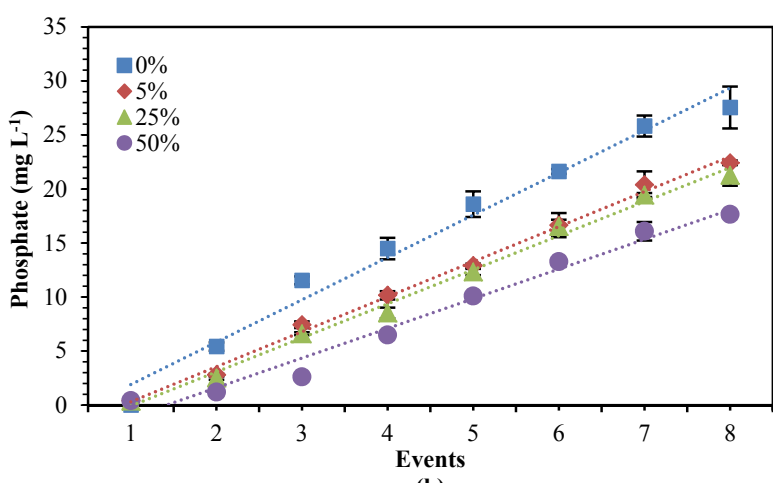

(b)

Figure 5. Phosphate concentration during (a) nutrients retention and (b) release

\subsubsection{Biochar Impact on Potassium Concentration}

The effect of biochar addition on potassium availability in the media is demonstrated in Figure 6. Unlike nitrate and phosphate, potassium retention and release followed exponential decay and logarithmic growth patterns. 
Comparing to the concentration of potassium in the in the leachate to its concentration in the stock solution which was $136 \mathrm{mg} \mathrm{L}^{-1}$, the reduction of potassium in the leachate at the end of the test was approximately 19, 21, and 25-26 mg L $\mathrm{m}^{-1}$ with 50, 25 and 5\% CSBC respectively. It can be noticed that the small percentage of biochar of 5\% had slightly similar effect on the retention as that of peatmoss. Interestingly, the medium amount of biochar of $25 \%$ stopped absorbing potassium after the fourth event and started releasing small amount of potassium after that. Some potassium release from media with $50 \%$ was also noticed at the end of the retention events. This indicates that for effective retention of potassium in the media, a low percentage of biochar of as low as $5 \%$ or less needs to be applied.

With regards to the release experiments, media with and without biochar had similar results for events at the beginning and the end. The highest release of potassium was from $50 \% \mathrm{BC}$ treated columns whereas the lowest was from the control treatment. The $50 \%$ CSBC released around $100 \mathrm{mg} \mathrm{L}^{-1}$, the other treatments released $95-97$ $\mathrm{mg} \mathrm{L}^{-1}$. For the events in the middle, the release was higher with the higher concentration of biochar. It can also be noticed that the amount of potassium released is higher than the absorbed potassium indicating the leaching of potassium form biochar structure. Similar results were reported by (Zhong et al., 2019; Palanivell et al., 2020). This can be an attractive trait for both hydroponic and soil-based agriculture as biochar can reduce the amount of potassium added to plants. Wu et al. (2019) found that the addition of biochar increased the availability of dissolved and bioavailable potassium in the soil.

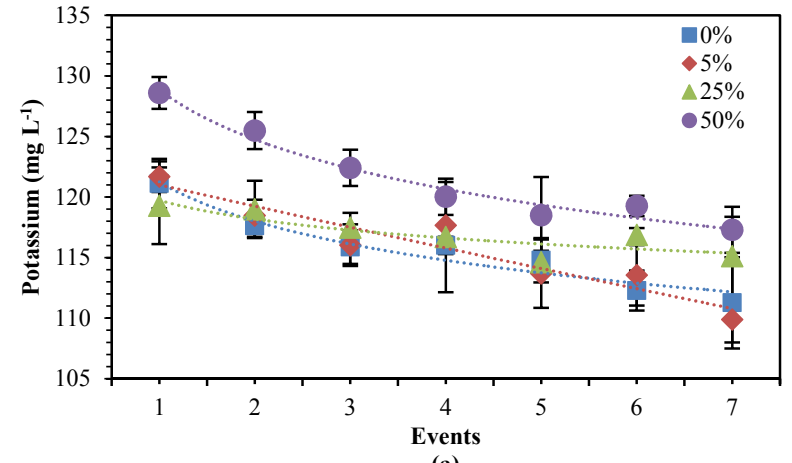

(a)

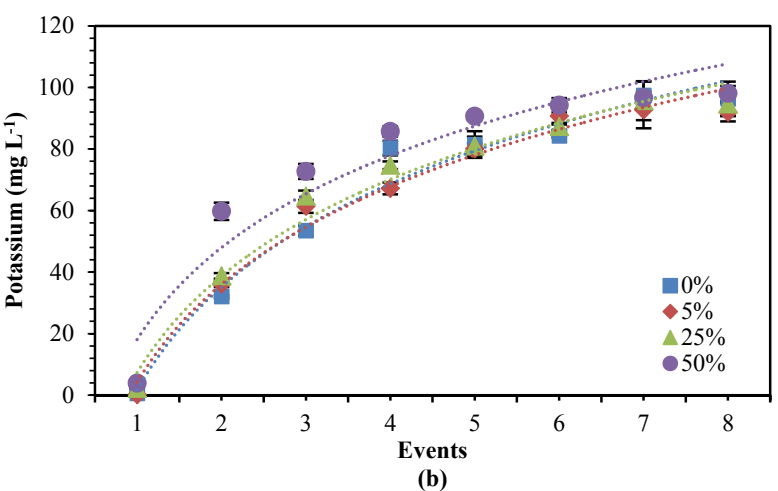

(b)

Figure 6. Potassium concentration during (a) nutrients retention and (b) release

\subsubsection{Biochar Impact on Calcium Concentration}

The effect of biochar on calcium interaction with the media is depicted in Figure 7. Calcium concentration in the effluent of the column followed a liner correlation with retention events in the case of $0 \%$ CSBC and exponential decay in the case of CSBC incorporation into the media. Interestingly, 5\% of CSBC had the highest retention of calcium followed by $25 \%$ CSBC and then $50 \%$ CSBC. This might could be attributed to calcium release from biochar structure when the applied CSBC percentage is high. When deionised water was passed through the column for recovering adsorbed calcium, the resultant concentrations exhibited linear correlations with the frequency of release events. A considerable amount of calcium remained in the column even after eight washes with deionised water. None of calcium was released in the first two events for all treatments. In comparison to the other measured nutrients so far, $0 \% \mathrm{CSBC}$ had the closest release amount of the absorbed element as opposed to other treatments. This suggests that peatmoss is effective for storing calcium. From the above, it can be said the combination of peatmoss and CSBC can effectively be used in hydroponics in order to reduce the use of fertiliser. There are limited researches on BC effects on calcium concentration in a solution, however, many authors have shown that biochar can enhance calcium availability in soils (Jien \& Wang, 2013). Our results showed that CSBC can adsorb calcium then slowly release it in the deionised water. 

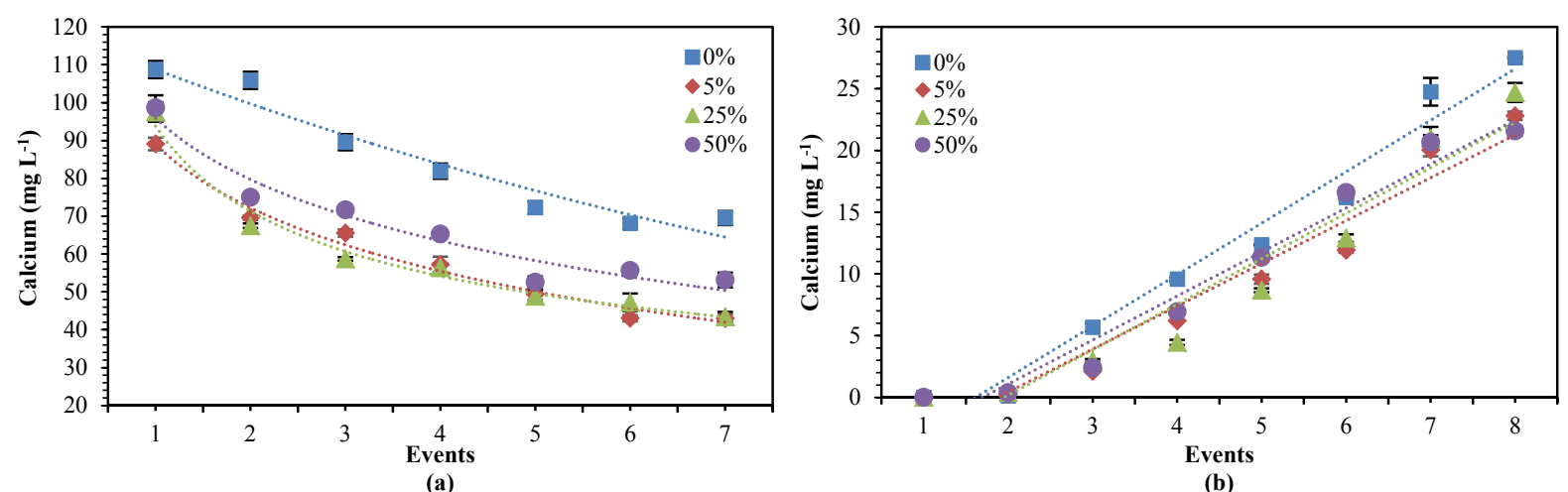

Figure 7. Calcium concentration during (a) nutrients retention and (b) release

\subsubsection{Biochar Impact on Magnesium Concentration}

The retention and release patterns of magnesium are demonstrated in Figure 8. It is clear that biochar did not affect magnesium concentration in the nutrient solution. The difference between the control treatment $(0 \% \mathrm{CSBC})$ and the other treatments was around $1 \mathrm{mg} \mathrm{L}^{-1}$. There was virtually no difference between magnesium concentrations in the effluent of the column for all of the treatments with biochar. However, surprisingly there was a release of magnesium when deionised water was used. The release exhibited a logarithmic growth trend. The released magnesium was higher as biochar ratio increased in the media. The highest release was around $15 \mathrm{mg} \mathrm{L}^{-1}$ with $50 \%$ CSBC, and it was around $13-14 \mathrm{mg} \mathrm{L}^{-1}$ with the other treatments. This suggests that deionised water stripped off magnesium from the structure of peatmoss and biochar. These results are in line with the findings of Angst \& Sohi. (2013). It was also shown by Kuhlbusch and Crutzen (1995) that burning biomass lead to producing ash which has magnesium. This could be the reasons why the mixture did not adsorb magnesium, rather released it. Mukherjee and $\mathrm{Lal}$ (2014) observed that $\mathrm{Mg}$ concentration decreased with increasing rate of biochar amendment.

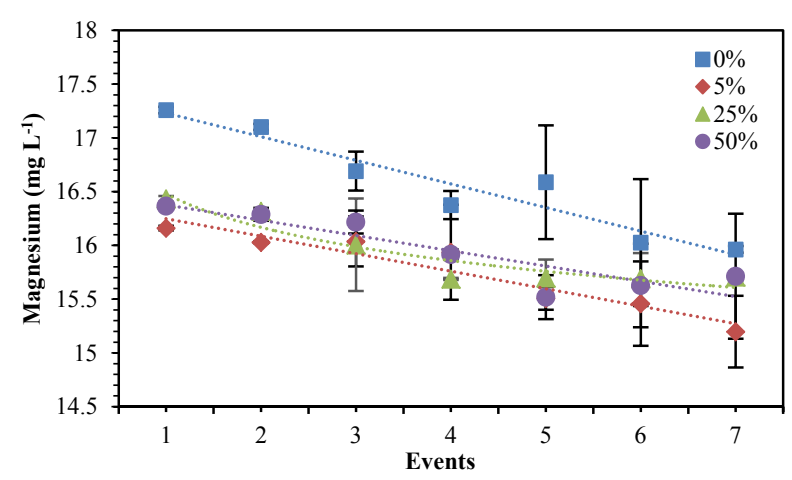

(a)

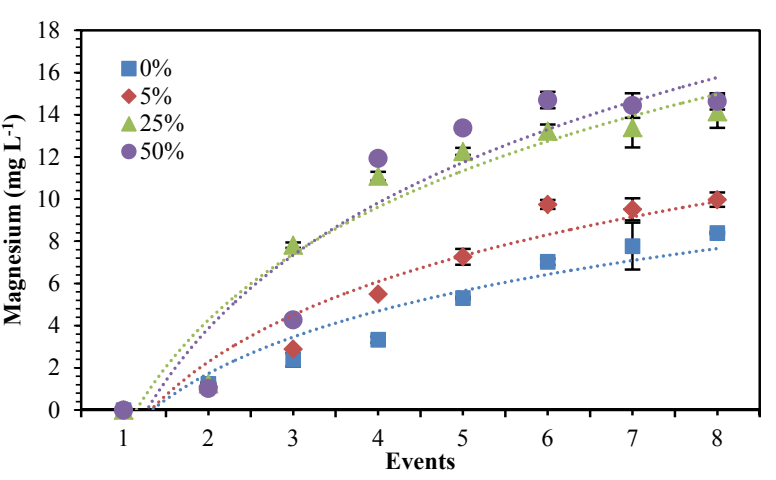

(b)

Figure 8. Magnesium concentration during (a) nutrients retention and (b) release

\subsubsection{Biochar Impact on Sulphate Concentration}

Figure 9 illustrates the effect of biochar ratio on sulphate sorption and desorption during 7 events. In general, CSBC improved the retention of sulphate and this improvement is directly related to the percentage of used CSBC. Compared to the initial concentration of sulphate $\left(140 \mathrm{mg} \mathrm{L}^{-1}\right)$, the retention was around $60 \mathrm{mg} \mathrm{L}^{-1}$ in the control treatment while it was around $100 \mathrm{mg} \mathrm{L}^{-1}$ with $50 \%$ CSBC. The $5 \%$ and $25 \% \mathrm{CSBC}$ treatments retained around 77 $\mathrm{mg} \mathrm{L}{ }^{-1}$ and $84 \mathrm{mg} \mathrm{L}^{-1}$, respectively.

In term of sulphate release during 8 events, $0 \% \mathrm{CSBC}$ released more sulphate than other treatments. The release of sulphate was around $60 \mathrm{mg} \mathrm{L}^{-1}, 37 \mathrm{mg} \mathrm{L}^{-1}, 30 \mathrm{mg} \mathrm{L}^{-1}$ and $11 \mathrm{mg} \mathrm{L}^{-1}$ from $0 \%, 5 \%, 25 \%$ and $50 \%$ treatments, respectively. The retention of sulphate could be due to the surface functional groups such as carboxylic group (Wang et al., 2015b), which is available in BC as it is the case of this study. The retention of sulphate could also be 
attributed to the high surface area $\left(1050 \mathrm{~m}^{2} \mathrm{~g}^{-1}\right.$ for CSBC used in this study, taken from the specification sheet) and porous structure of such char (Verheijen et al., 2010; Lehmann \& Joseph, 2015).
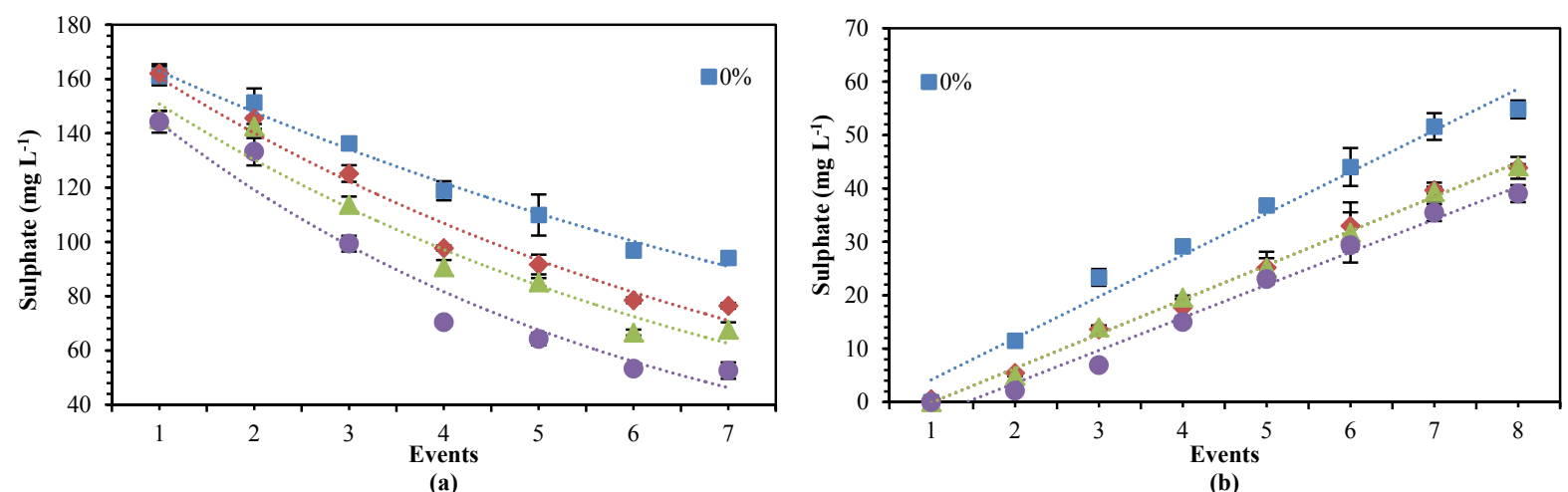

Figure 9. Sulphate concentration during (a) nutrients retention and (b) release

\subsection{Nutrient Trends With Biochar Addition}

Macronutrient adsorption and desorption in biochar exhibited different trends with time. The trends were either exponential $\left(y=m \cdot e^{-c x}\right)$ or power $\left(y=m \cdot x^{-c}\right)$ for adsorption whereas linear $(y=m x+c)$ and logarithmic $(y=m \cdot \ln (x)$ $+c$ ) for desorption. Adsorption of phosphate and Sulphate fitted with an exponential trend as well as potassium at 0 and 5\% CSBC and calcium at $0 \% \mathrm{CSBC}$ level. In comparison, nitrate, potassium at 25 and $50 \%$ CSBC as well as calcium at 5, 25 and 50\% CSBC levels fitted well with the power trend. Magnesium was the only element which fitted with a linear trend. At the desorption phase, all nutrients fitted showed linear trends except potassium at all CSBC levels and magnesium at 25 and 50\% CSBC levels were fitted with logarithmic trends.

\section{Conclusions}

The effects of CSBC addition to hydroponic growth media on $\mathrm{pH}, \mathrm{EC}$ and nutrient levels were investigated using column experiments. As expected, $\mathrm{pH}$ increased as the CSBC amount increased in the media. In terms of EC, biochar affected EC levels in line with the effective charge capacity accommodated by the integrated carbon. As expected, without inherant storage capabilities the control treatment released elements more than all other treatments, while the highest recovery of the elements was from the growth media with $50 \%$ CSBC. Nitrate, phosphate, calcium, potassium and sulphate were all effectively retained by CSBC while magnesium levels were not significantly impacted. We recommend using CSBC levels at an average rate of $25 \%$ of the growth media or slightly lower in hydroponic systems, while $50 \%$ for use as suitable treatment for optimal water filtration. Bearing in mind that more than $50 \%$ of CSBC in treatments is beyond the desirable limit for crop cultivation (Depending on the type and pyrolysis temperature of the $\mathrm{BC}$ ). This study helped in establishing an understanding of the effect of biochar addition on a simulated closed loop hydroponics system. By testing the recommended biochar percentage on growth and yield quality it is possible to establish a simple approach that allowed a near identical yield with approximately half of the applied nutrients. Of course, further trials in field or greenhouse studies are recommended for future work on a broader range of plants.

\section{Acknowledgements}

Mohammed Taha Haraz is grateful for the financial support provided by the Ministry of Higher Education and Scientific Research and the University of Southern Queensland during his PhD study.

\section{References}

Altland, J. E., \& Locke, J. C. (2012). Biochar affects macronutrient leaching from a soilless substrate. HortScience, 47, 1136-1140. https://doi.org/10.21273/HORTSCI.47.8.1136

Angst, T. E., \& Sohi, S. P. (2013). Establishing release dynamics for plant nutrients from biochar. Gcb Bioenergy, 5, 221-226. https://doi.org/10.1111/gcbb.12023

Bakly, S., Al-Juboori, R. A., \& Bowtell, L. (2019). Macadamia Nutshell Biochar for Nitrate Removal: Effect of Biochar Preparation and Process Parameters. C-Journal of Carbon Research, 5, 47. https://doi.org/ $10.3390 / \mathrm{c} 5030047$ 
Barbosa, G. L., Gadelha, F. D. A., Kublik, N., Proctor, A., Reichelm, L., Weissinger, E., ... Halden, R. U. (2015). Comparison of land, water, and energy requirements of lettuce grown using hydroponic vs. conventional agricultural methods. International Journal of Environmental Research and Public Health, 12, 6879-6891. https://doi.org/10.3390/ijerph120606879

Bar-Yosef, B. (2008). Fertigation management and crops response to solution recycling in semi-closed greenhouses. Soilless Culture: Theory and Practice (pp. 343-424). Elsevier, Amsterdam. https://doi.org/ 10.1016/B978-044452975-6.50011-3

Beck, D. A., Johnson, G. R., \& Spolek, G. A. (2011). Amending greenroof soil with biochar to affect runoff water quantity and quality. Environmental Pollution, 159, 2111-2118. https://doi.org/10.1016/j.envpol. 2011.01.022

Borchard, N., Wolf, A., Laabs, V., Aeckersberg, R., Scherer, H. W., Moeller, A., \& Amelung, W. (2012). Physical activation of biochar and its meaning for soil fertility and nutrient leaching-a greenhouse experiment. Soil Use and Management, 28, 177-184. https://doi.org/10.1111/j.1475-2743.2012.00407.x

Bruinsma, J. (2011). The resources outlook: by how much do land, water and crop yields need to increase by 2050? Looking ahead in world food and agriculture: Perspectives to 2050 (pp. 233-278).

Carmassi, G., Incrocci, L., Maggini, R., Malorgio, F., Tognoni, F., \& Pardossi, A. (2005). Modeling salinity build-up in recirculating nutrient solution culture. Journal of Plant Nutrition, 28, 431-445. https://doi.org/10.1081/PLN-200049163

Davidson, A. A., \& Szmidt, R. A. K. (1992). Hydroponic crop production.

Ding, Y., Liu, Y.-X., Wu, W.-X., Shi, D.-Z., Yang, M., \& Zhong, Z.-K. (2010). Evaluation of biochar effects on nitrogen retention and leaching in multi-layered soil columns. Water, Air, \& Soil Pollution, 213, 47-55. https://doi.org/10.1007/s11270-010-0366-4

Gai, X., Wang, H., Liu, J., Zhai, L., Liu, S., Ren, T., \& Liu, H. (2014). Effects of feedstock and pyrolysis temperature on biochar adsorption of ammonium and nitrate. PloS One, 9. https://doi.org/10.1371/journal. pone.0113888

Gashgari, R., Alharbi, K., Mughrbil, K., Jan, A., \& Glolam, A. (2018). Comparison between growing plants in hydroponic system and soil based system. Proceedings of the 4th World Congress on Mechanical, Chemical, and Material Engineering (pp. 1-7). ICMIE Madrid, Spain. https://doi.org/10.11159/icmie18.131

Glaser, B., Lehmann, J., \& Zech, W. (2002). Ameliorating physical and chemical properties of highly weathered soils in the tropics with charcoal-a review. Biology and Fertility of Soils, 35, 219-230. https://doi.org/ 10.1007/s00374-002-0466-4

Graber, E. R., Harel, Y. M., Kolton, M., Cytryn, E., Silber, A., David, D. R., ... Elad, Y. (2010). Biochar impact on development and productivity of pepper and tomato grown in fertigated soilless media. Plant and Soil, 337, 481-496. https://doi.org/10.1007/s11104-010-0544-6

Grewal, H. S., Maheshwari, B., \& Parks, S. E. (2011). Water and nutrient use efficiency of a low-cost hydroponic greenhouse for a cucumber crop: An Australian case study. Agricultural Water Management, 98, 841-846. https://doi.org/10.1016/j.agwat.2010.12.010

Hochmuth, R., Leon, L. L., Crocker, T., Dinkins, D., \& Hochmuth, G. (1998). Evaluation of two soilless growing media and three fertilizer programs in outdoor bag culture for strawberry in North Florida. Proceedings of the Florida State Horticultural Society (pp. 341-343).

Jien, S.-H., \& Wang, C.-S. (2013). Effects of biochar on soil properties and erosion potential in a highly weathered soil. Catena, 110, 225-233. https://doi.org/10.1016/j.catena.2013.06.021

Keiluweit, M., Nico, P. S., Johnson, M. G., \& Kleber, M. (2010). Dynamic molecular structure of plant biomass-derived black carbon (biochar). Environmental science \& technology, 44, 1247-1253. https://doi.org/10.1021/es9031419

Koehorst, R., Laubscher, C. P., \& Ndakidemi, P. A. (2010). Growth response of Artemisia afra Jacq. to different $\mathrm{pH}$ levels in a closed hydroponics system. Journal of Medicinal Plants Research, 4, 1617-1623.

Kuhlbusch, T. A. J., \& Crutzen, P. J. (1995). Toward a global estimate of black carbon in residues of vegetation fires representing a sink of atmospheric $\mathrm{CO}_{2}$ and a source of $\mathrm{O}_{2}$. Global Biogeochemical Cycles, 9, 491-501. https://doi.org/10.1029/95GB02742 
Lehmann, J. \& Joseph, S. (2015). Biochar for Environmental Management: Science, Technology and Implementation. Routledge.

Lehmann, J. (2007). Bio-energy in the black. Frontiers in Ecology and the Environment, 5, $381-387$. https://doi.org/10.1890/1540-9295(2007)5[381:BITB]2.0.CO;2

Mukherjee, A., \& Lal, R. (2014). The biochar dilemma. Soil Research, 52, 217-230. https://oi.org/10.1071/ SR13359

Nelson, N. O., Agudelo, S. C., Yuan, W., \& Gan, J. (2011). Nitrogen and phosphorus availability in biochar-amended soils. Soil Science, 176, 218-226. https://doi.org/10.1097/SS.0b013e3182171 eac

Novak, J. M., Lima, I., Xing, B., Gaskin, J. W., Steiner, C., Das, K. C., ... Busscher, W. J. (2009). Characterization of designer biochar produced at different temperatures and their effects on a loamy sand. Annals of Environmental Science, 3(1), 195-206.

Palanivell, P., Ahmed, O. H., Latifah, O., Majid, A., \& Muhamad, N. (2020). Adsorption and Desorption of Nitrogen, Phosphorus, Potassium, and Soil Buffering Capacity Following Application of Chicken Litter Biochar to an Acid Soil. Applied Sciences, 10, 295. https://doi.org/10.3390/app10010295

Putra, P. A., \& Yuliando, H. (2015). Soilless culture system to support water use efficiency and product quality: A review. Agriculture and Agricultural Science Procedia, 3, 283-288. https://doi.org/10.1016/j.aaspro. 2015.01.054

Raviv, M., Lieth, J. H., \& Bar-Tal, A. (2019). Soilless Culture: Theory and Practice: Theory and Practice. Elsevier.

Rice, E. W., Baird, R. B., Eaton, A. D. \& Clesceri, L. S. (2017). Standard Methods for the Examination of Water and Wastewater (23rd ed.). Washington, DC: American Public Health Association.

Rouphael, Y., Colla, G., Battistelli, A., Moscatello, S., Proietti, S., \& Rea, E. (2004). Yield, water requirement, nutrient uptake and fruit quality of zucchini squash grown in soil and closed soilless culture. The Journal of Horticultural Science and Biotechnology, 79, 423-430. https://doi.org/10.1080/14620316.2004.11511784

Savvas, D. (2002). SW-Soil and Water: Automated replenishment of recycled greenhouse effluents with individual nutrients in hydroponics by means of two alternative models. Biosystems Engineering, 83, 225-236. https://doi.org/10.1006/bioe.2002.0106

United States Environmental Protection Agency Office of Solid Waste. (1994). Characterization of Municipal Solid Waste in the United States: 1994 Update. US Environmental Protection Agency, Solid Waste and Emergency Response.

Valenzano, V., Parente, A., Serio, F., \& Santamaria, P. (2008). Effect of growing system and cultivar on yield and water-use efficiency of greenhouse-grown tomato. The Journal of Horticultural Science and Biotechnology, 83, 71-75. https://doi.org/10.1080/14620316.2008.11512349

Verheijen, F., Jeffery, S., Bastos, A. C., Van der Velde, M., \& Diafas, I. (2010). Biochar application to soils: A critical scientific review of effects on soil properties, processes, and functions. EUR, 24099, 162.

Wang, H., Gao, B., Wang, S., Fang, J., Xue, Y., \& Yang, K. (2015a). Removal of Pb (II), Cu (II), and Cd (II) from aqueous solutions by biochar derived from $\mathrm{KMnO}_{4}$ treated hickory wood. Bioresource Technology, 197, 356-362. https://doi.org/10.1016/j.biortech.2015.08.132

Wang, Z., Guo, H., Shen, F., Yang, G., Zhang, Y., Zeng, Y., ... Deng, S. (2015b). Biochar produced from oak sawdust by Lanthanum (La)-involved pyrolysis for adsorption of ammonium $\left(\mathrm{NH}_{4}^{+}\right)$, nitrate $\left(\mathrm{NO}_{3}{ }^{-}\right)$, and phosphate $\left(\mathrm{PO}_{4}{ }^{3-}\right)$. Chemosphere, 119, 646-653. https://doi.org/10.1016/j.chemosphere.2014.07.084

Wortman, S. E. (2015). Crop physiological response to nutrient solution electrical conductivity and $\mathrm{pH}$ in an ebb-and-flow hydroponic system. Scientia Horticulturae, 194, 34-42. https://doi.org/10.1016/j.scienta. 2015.07.045

Wu, X., Wang, D., Riaz, M., Zhang, L., \& Jiang, C. (2019). Investigating the effect of biochar on the potential of increasing cotton yield, potassium efficiency and soil environment. Ecotoxicology and Environmental Safety, 182, 109451. https://doi.org/10.1016/j.ecoenv.2019.109451

Yao, Y., Gao, B., Zhang, M., Inyang, M., \& Zimmerman, A. R. (2012). Effect of biochar amendment on sorption and leaching of nitrate, ammonium, and phosphate in a sandy soil. Chemosphere, 89, 1467-1471. https://doi.org/10.1016/j.chemosphere.2012.06.002 
Zhong, Z., Yu, G., Mo, W., Zhang, C., Huang, H., Li, S., ... Zhu, H. (2019). Enhanced phosphate sequestration by Fe (iii) modified biochar derived from coconut shell. RSC Advances, 9, 10425-10436. https://doi.org/ 10.1039/C8RA10400J

\section{Copyrights}

Copyright for this article is retained by the author(s), with first publication rights granted to the journal.

This is an open-access article distributed under the terms and conditions of the Creative Commons Attribution license (http://creativecommons.org/licenses/by/4.0/). 